\title{
Rancang Bangun Sistem Informasi Rekam Medis (Studi Kasus: Klinik PKU Muhammadiyah Gandrungmangu)
}

\author{
Design of Medical Record Information System \\ (Case Study : PKU Muhammadiyah Gandrungmangu Clinic) \\ Fathan Asyhari ${ }^{1}$, Aridhanyati Arifin ${ }^{2 *}$ \\ ${ }^{1,2}$ Program Studi Informatika Fakultas Teknologi Industri, Universitas Islam Indonesia
}

\section{ARTICLE INFO}

Article history:

DOI:

$\underline{10.30595 / \text { pspfs.v1i. } 147}$

Submitted:

June 28, 2021

Accepted:

July 10,2021

Published:

ABSTRACT

Health Services at the PKU Muhammadiyah Gandrungmangu Clinic have not made much use of information technology. Documentation of patient medical records still uses a manual recording system, causing various obstacles; for example, officers often find the same medical record number and difficulties making reports. Thus, creating a medical record information system is necessary to help manage medical record data electronically. The system was developed using the prototyping method. This system has several features: medical record management, user management, reporting system, input checking feature for vital sign results, uploading feature for supporting examination results, and patient queuing system for each poly. The results of the user convenience test using the SEQ method obtained an average value of 6 and 7. The usability test results using the SUS method also got a good response from the questionnaire questions given to the respondents, which got a total score of 90.6 , meaning that the system has an excellent usability level.
\end{abstract}

Oct 31,2021

Keywords:

Prototyping method, medical record, SEQ, information system, SUS
This work is licensed under a Creative Commons Attribution 4.0 International License.

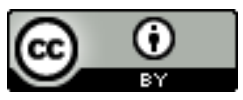

\section{Corresponding Author:}

Aridhanyati Arifin

Program Studi Informatika Fakultas Teknologi Industri, Universitas Islam Indonesia

J1. Kaliurang KM. 14,5 Sleman Yogyakarta 55584 Telp. +62 274895287 ext. 4148

Email: aridhanyati@uii.ac.id

\section{PENDAHULUAN}

Rekam medis merupakan kegiatan pencatatan yang wajib dilakukan oleh dokter atau petugas medis yang memberikan pelayanan atau tindakan kepada pasien (RI, 2004). Umumnya data rekam medis tersimpan dalam map yang berisi kertas-kertas yang mencatat data kesehatan pasien. Dalam rekam medis berisi data tentang identitas pasien, pemeriksaan, pengobatan, tindakan, dan pelayanan lain yang telah diberikan kepada pasien (RI, 2004).

Pemanfaatan teknologi informasi di bidang kesehatan telah menjadi kecenderungan pelayanan kesehatan masyarakat global. Negara-negara maju umumnya sudah banyak yang menggunakan sistem informasi rumah sakit/klinik atau rekam medis elektronik (Amin et.al, 2021). Rekam medis elektronik menjadi substitusi maupun pendamping dari rekam medis yang berbentuk kertas. Data tersebut dapat membantu sebagai rujukan oleh dokter untuk pemeriksaan kesehatan pasien selanjutnya. Keberadaan sistem informasi atau rekam medis elektronik pada pusat-pusat pelayanan kesehatan tersebut dapat meningkatkan kualitas pelayanan kesehatan, baik dari sisi akurasi dan efisiensi (Andriani \& Kusnanto, 2017). Fasilitas layanan kesehatan di negara-negara berkembang termasuk Indonesia, belum banyak didukung oleh sistem informasi atau rekam medis elektronik (Amien et.al, 2021). Sebagaimana yang terdapat di Klinik PKU Muhammadiyah Gandrungmangu, pencatatan rekam medis secara konvensional (dengan kertas) menimbulkan beberapa masalah misalnya kesulitan dalam pencarian berkas rekam medis, besarnya sumber 
daya yang harus dikeluarkan untuk menyusun laporan, kelambatan pencatatan dan pelayanan di bagian pendaftaran, pemeriksaan hingga pengambilan obat. Jika persoalan tersebut tidak segera ditangani maka lambat laun akan menurunkan kualitas pelayanan kesehatan.

Berdasarkan permasalahan tersebut, maka diperlukan solusi teknologi informasi yang dapat membantu klinik PKU Muhammadiyah Gandrungmangu dalam mengelola data rekam medis. Sistem tersebut mampu memenuhi standar dalam pembuatan struktur dan isi rekam medis, serta kerahasiaan dan keamanan data rekam medis terjamin (Rusli et al., 2006). Sistem informasi rekam medis telah berhasil menjadi solusi di berbagai fasilitas kesehatan seperti klinik, puskesmas dan rumah sakit. Manfaatnya utamanya adalah tersedianya data dalam satu repository sehing ga dapat mendukung penegakan keputusan klinis dan keselamatan pasien (Erawantini dan Wibowo, 2019).

Fokus pembahasan makalah adalah menguraikan proses pengembangan sistem informasi rekam medis dan melakukan analisis pada hasil pengujian yang dilakukan terhadap pengguna sistem informasi rekam medis untuk menentukan apakah sistem yang dibuat dapat mengefisienkan pengelolaan rekam medis pada klinik.

\section{METODE PENELITIAN}

Bagian ini akan menguraikan tahapan-tahapan penelitian yang dilakukan, yaitu :

1. Kajian literatur. Tahap ini ditujukan untuk mendapatkan fokus dan batasan penelitian. Aktivitas yang dilakukan berupa kajian terhadap sejumlah hasil penelitian terdahulu yang mengangkat topik rekam medis elektronik dan sistem informasi rekam medis. Kajian tersebut menghasilkan informasi mengenai fitur-fitur apa saja yang biasanya ada dalam suatu rekam medis elektronikS seperti manajemen dokter, manajemen data rekam medis, laporan kunjungan (Prasetyo dan Azis, 2018), rujukan pasien (Hakim, 2019), halaman profil (Kurnia, 2019) dan grafik kunjungan pasien. Penelitian ini akan menutupi kekurangan dari penelitian sebelumnya yaitu dengan cara menggabungkan fitur-fitur utama dari penelitian sebelumnya yang dapat menunjang kebutuhan pengguna dalam mengelola data rekam medis ditambah fitur untuk mengecek input hasil vital sign agar sesuai dengan aturan medis yang berlaku, fitur yang dapat mengunggah hasil pemeriksaan penunjang pada saat pemeriksaan pasien, sistem antrian pasien untuk setiap poli, laporan 10 besar penyakit, laporan sensus harian untuk setiap poliklinik, dan laporan morbiditas rawat jalan.

2. Perencanaan. Pada tahap ini ditetapkan lokasi studi kasus dan memilih metode prototyping sebagai metode pengembangan perangkat lunak dan teknik pengujian yang akan digunakan. Metode ini digunakan agar sistem yang dibuat mendapatkan umpan balik yang cepat dari pengguna yang membantu peneliti menentukan fitur sistem agar sesuai dengan ekspektasi dan kebutuhan pengguna yang sebenarnya (Subhiyakto \& Utomo, 2017).

3. Pengembangan perangkat lunak dengan menjalankan 4 tahap metode prototyping (Pressman, 2012), yaitu :

a) Communication, yaitu aktivitas menggali kebutuhan kepada kepala klinik melalui teknik wawancara.

b) Quick plan \& Modeling Quick design, yaitu analisis terhadap kebutuhan pengguna dan membuat pemodelan.

c) Construction of prototype, yaitu membuat prototipe sistem informasi rekam medis berbasis web.

d) Deployment, Delivery \& Feedback, yaitu pengguna melakukan uji coba terhadap prototipe kemudian dilakukan evaluasi kemudian pengguna memberikan feedback untuk perbaikan. Pengujian menggunakan metode Single Ease Question (SEQ) dan (System Usability Scale) SUS. Metode SEQ digunakan untuk mengukur kemudahan pengguna dalam menjalankan semua task yang diberikan (Sauro \& Lewis, 2012) dan metode SUS dipakai untuk mengukur kinerja usabilitas dari desain sistem informasi rekam medis (Brooke, 2013).

\section{HASIL DAN PEMBAHASAN}

Penerapan metode prototyping dalam pembangunan Sistem Informasi Rekam Medis Klinik PKU Muhammadiyyah Gandrumangu, mengalami dua kali iterasi yang rinciannya dapat dilihat dalam Tabel 1.

Tabel 1. Proses Iterasi dalam Pengembangan Sistem Informasi Rekam Medis

\begin{tabular}{lll}
\hline Tahapan & Iterasi 1 & Iterasi 2 \\
\hline Communication & Hasil wawancara, diketahui proses bisnis & Hasil wawancara diperoleh penambahan dan \\
& klinik dan fitur yang diinginkan adalah : profil & perbaikan desain fitur yaitu: perubahan letak \\
& klinik, pendaftaran, pemeriksaan vital, tombol navigasi, perubahan desain kotak \\
& diagnosis penyakit, resep obat, penomoran dialog menjadi pop-up. Tambahan halaman \\
rekam medis otomatis, laporan harian dan & dashboard untuk user resepsionis, perawat, \\
& tahunan dan fitur pencarian data & antrian yang ada pada hari itu. Tambahan \\
& & halaman dashboard untuk user admin yang \\
& berisikan informasi tentang kunjungan perhari \\
& untuk setiap poli klinik, kunjungan pertahun, \\
\hline
\end{tabular}


dan 10 besar penyakit. Tambahan tombol cetak kartu berobat pada daftar pasien terdaftar.

Quick plan \& pemodelan menggunakan Use Case Diagram Modeling Quick , Activity Diagram, dan relasi antar tabel basis design data

Construction of Merancang prototipe prototype Deployment, Delivery, Menyerahkan prototipe sistem kepada \& pengguna kemudian dilakukan uji coba dan Feedback evaluasi pertama. Hasilnya diperlukan beberapa perbaikan dan penambahan fitur.
Perubahan pada desain antarmuka tetapi tidak mengubah desain fungsi sistem dan basis data

Menerapkan perubahan pada prototipe sistem

Menyerahkan prototipe sistem kepada pengguna kemudian dilakukan uji coba dan evaluasi kedua. Hasilnya prototipe dapat diterima oleh pengguna.

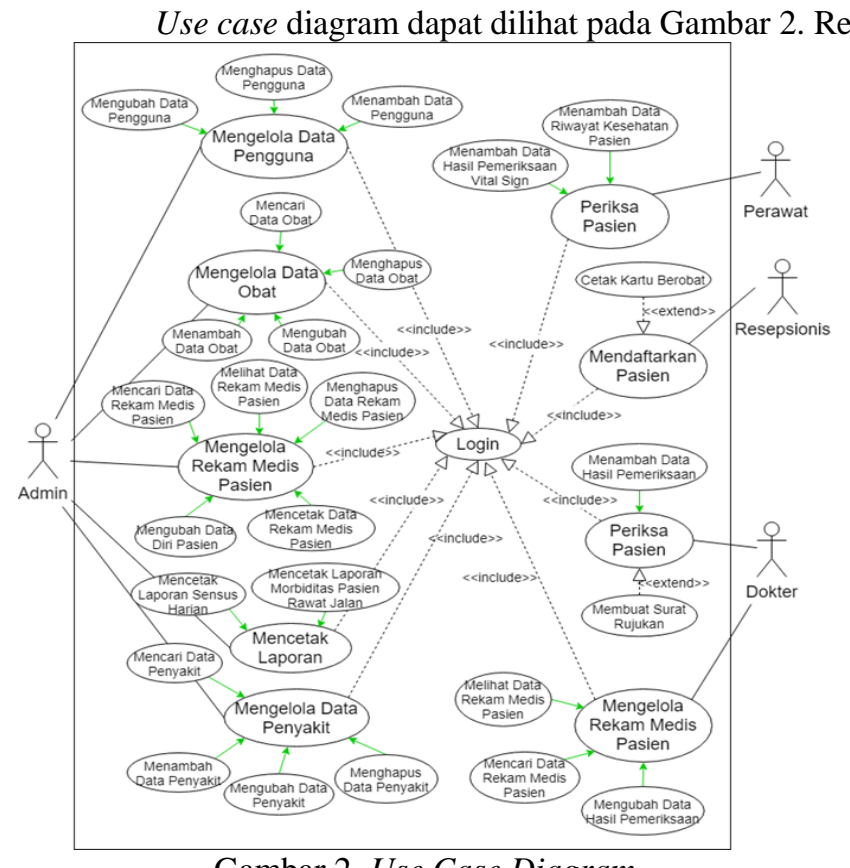

Gambar 2. Use Case Diagram

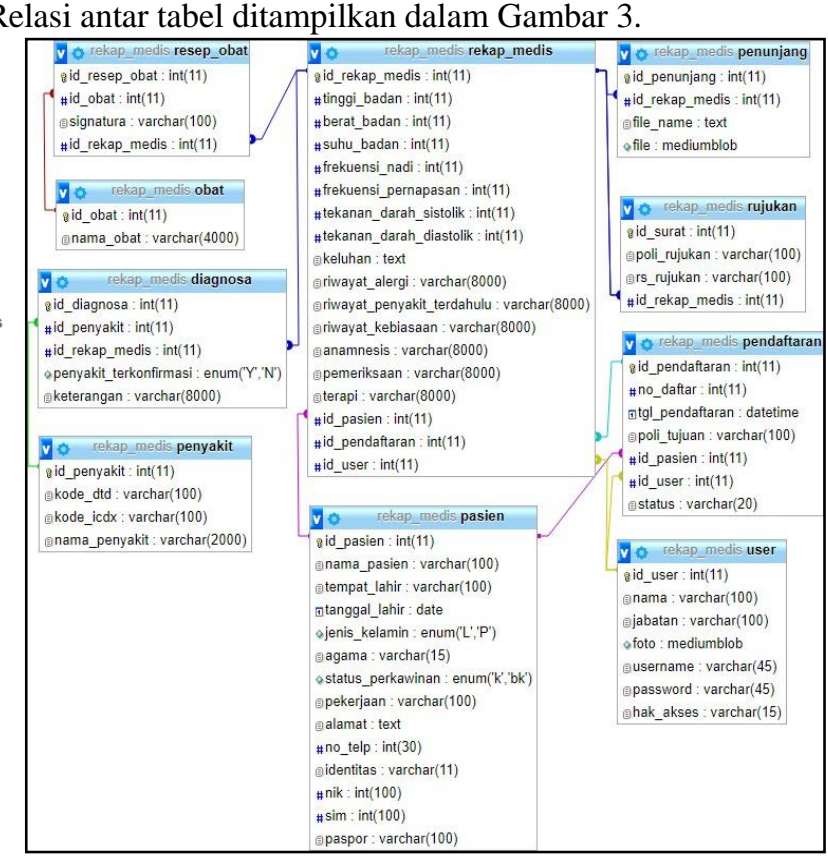

Gambar 3. Relasi Antar Tabel

Proses bisnis Sistem Informasi Rekam Medis Klinik PKU Muhammadiyyah Gandrumangu yaitu: (1) Pada saat pasien datang, pasien akan ditanya apakah sudah pernah berobat di klinik. (2) Jika sudah pernah maka petugas akan mencari data pasien dengan menggunakan nomor rekam medis atau nomor identitas pasien pada sistem. Apabila petugas tidak menemukan data pasien maka petugas akan mendaftarkan pasien pada sistem sebagai pasien baru sama seperti pasien yang belum pernah berobat di klinik. (3) Setelah melakukan pendaftaran maka data pasien akan muncul pada antrian poli yang dituju pasien dan perawat dapat memulai pemeriksaan tanda vital dengan menginputkan data tinggi badan, berat badan, suhu badan, frekuensi nadi, frekuensi pernapasan, tekanan darah sistolik, dan tekanan darah diastolik. (4) Data pasien tersebut akan berpindah ke antrian yang sudah melakukan pemeriksaan vital sign. (5) Dokter dapat melakukan diagnosis serta tindakan kemudian mencatat hasilnya ke dalam sistem dengan cara menambahkan anamnesis, terapi yang diberikan, menambahkan hasil diagnosis penyakit, dan menambahkan resep dari obat yang diberikan kepada pasien. Tampilan antarmuka Sistem Informasi Rekam Medis Klinik PKU Muhammadiyyah Gandrumangu dapat dilihat pada Gambar 4, Gambar 5 dan Gambar 6. 


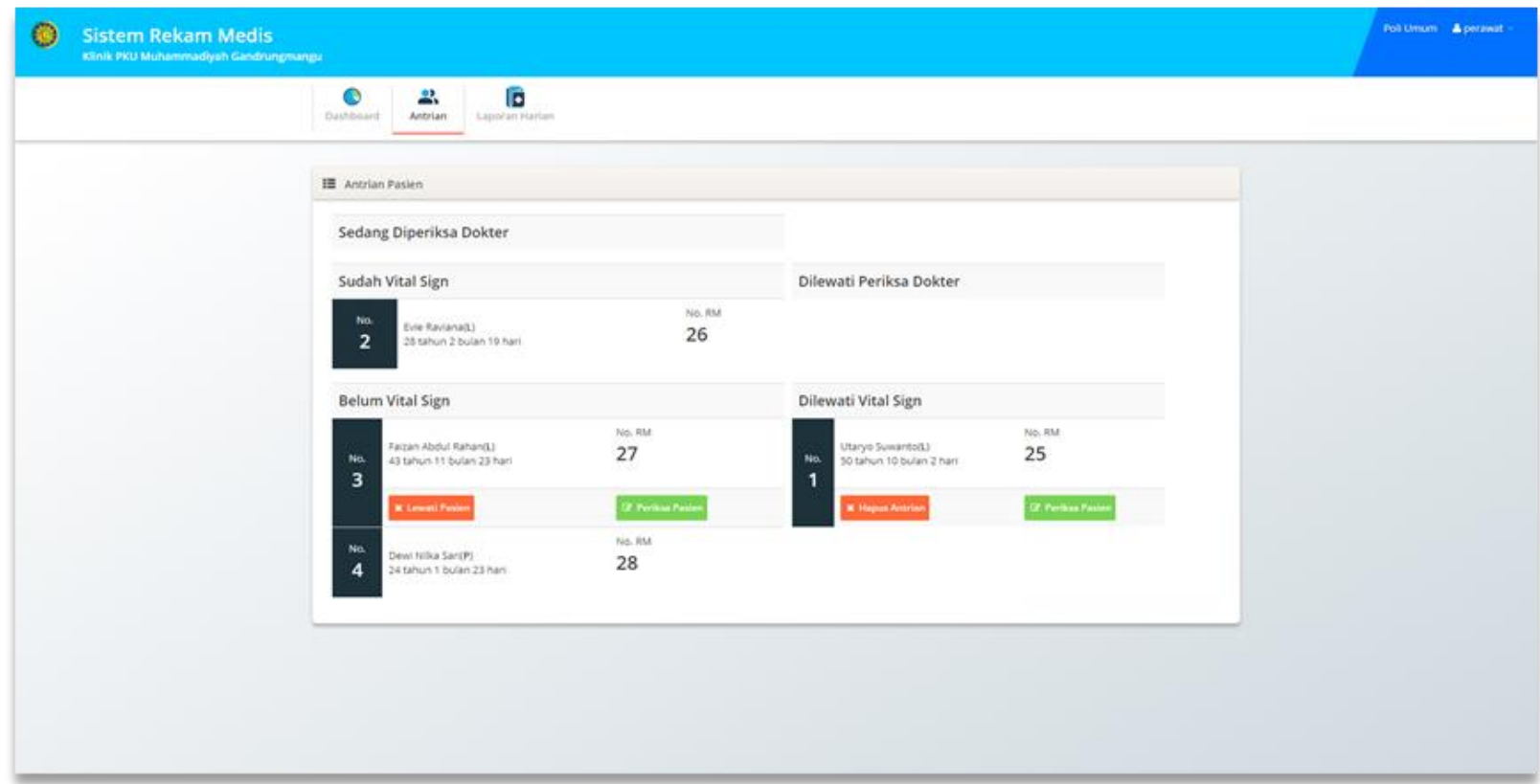

Gambar 4. Tampilan Antarmuka Halaman Antrian Pasien

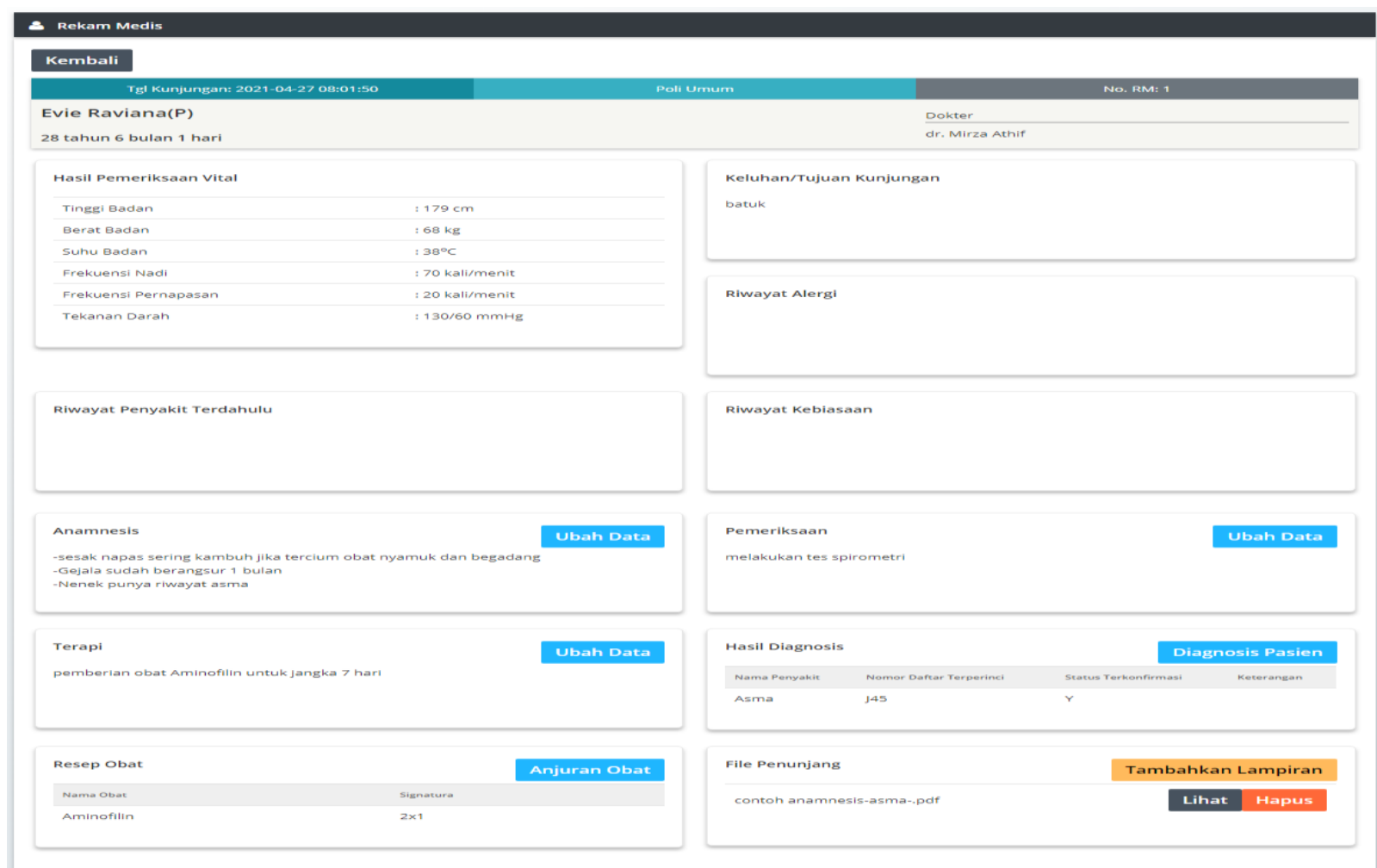

Gambar 5. Tampilan Antarmuka Halaman Pemeriksaan dan Pengisian Rekam Medis oleh Dokter 


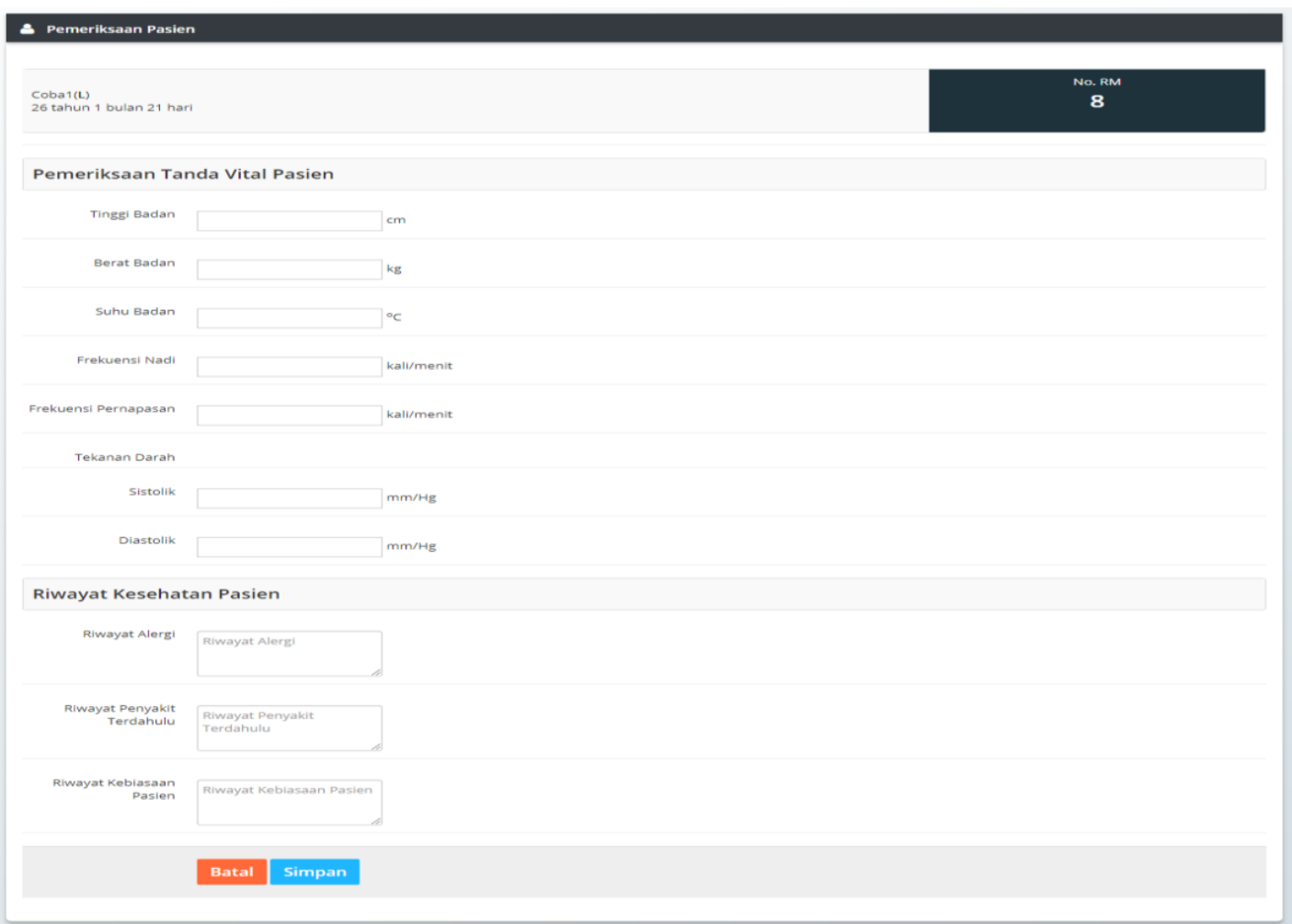

Gambar 6. Tampilan Antarmuka Halaman Pemeriksaan Tanda Vital Pasien

Pengujian pada penelitian ini dilakukan dengan dua tahap pengujian yaitu menggunakan metode SEQ dan SUS. Responden diminta untuk mengisikan jawaban pada setiap pernyataan/pertanyaan setelah mencoba sistem secara keseluruhan, data yang didapatkan kemudian dianalisis dan diolah untuk didapatkan kesimpulan.

1. Pengujian dengan metode SEQ

Pengujian SEQ ini diberikan kepada perwakilan responden yang dibagi menjadi empat pengguna yaitu resepsionis, perawat, dokter, dan admin. Responden diminta mengerjakan semua task/tugas pada skenario pengujian kemudian mengisi form dengan membubuhkan jawaban ya atau tidak. Jika responden memilih ya artinya fungsi tersebut mudah dilakukan dan digunakan tetapi jika tidak artinya fungsi tersebut sulit digunakan. Selanjutnya responden memilih salah satu skala likert 1-7, level dari sangat sulit, sulit, tidak mudah, cukup, tidak sulit, mudah, hingga sangat mudah, dengan tujuan untuk mengetahui tingkat kemudahan dalam menggunakan sistem pada setiap skenario. Tabel 2 merupakan salah satu contoh skenario pengujian untuk pengguna dokter.

Tabel 2. Skenario Pengujian SEQ

\begin{tabular}{|c|c|c|c|c|c|}
\hline No & Nama Fungsi & Task/Tugas & No & Nama Fungs & Task/Tugas \\
\hline F01 & Login & $\begin{array}{l}\text { Memasukan username dan } \\
\text { password untuk login ke dalam } \\
\text { sistem. }\end{array}$ & F06 & $\begin{array}{l}\text { Mengubah data } \mathrm{r} \\
\text { medis pasien }\end{array}$ & $\begin{array}{l}\text { rekamMengubah data rekam medis } \\
\text { pasien. }\end{array}$ \\
\hline F02 & lokasi & $\begin{array}{l}\text { i Memilih lokasi poli tempat } \\
\text { praktik dokter. }\end{array}$ & F07 & $\begin{array}{l}\text { Mengubah } \\
\text { pengguna }\end{array}$ & $\begin{array}{l}\text { dataMengubah nama, jabatan, } \\
\text { username, password, dan foto } \\
\text { profil pengguna. }\end{array}$ \\
\hline F03 & $\begin{array}{l}\text { Memeriksa } \\
\text { pasien }\end{array}$ & $\begin{array}{l}\text { Menginput hasil anamnesis, } \\
\text { pemeriksaan yang dilakukan, } \\
\text { terapi yang diberikan, hasil } \\
\text { diagnosis, resep obat yang } \\
\text { diberikan, mengunggah file } \\
\text { penunjang, dan membuat serta } \\
\text { mencetak surat rujukan. }\end{array}$ & F08 & Logout & $\begin{array}{l}\text { Melakukan logout untuk keluar } \\
\text { dari sistem. }\end{array}$ \\
\hline F05 & $\begin{array}{l}\text { Menghapus } \\
\text { pasien dari } \\
\text { antrian }\end{array}$ & $\begin{array}{l}\text { Menghapus pasien dari antrian } \\
\text { ijika pasien masih tidak kunjung } \\
\text { datang ketika dipanggil } \\
\text { kembali. }\end{array}$ & & & \\
\hline
\end{tabular}



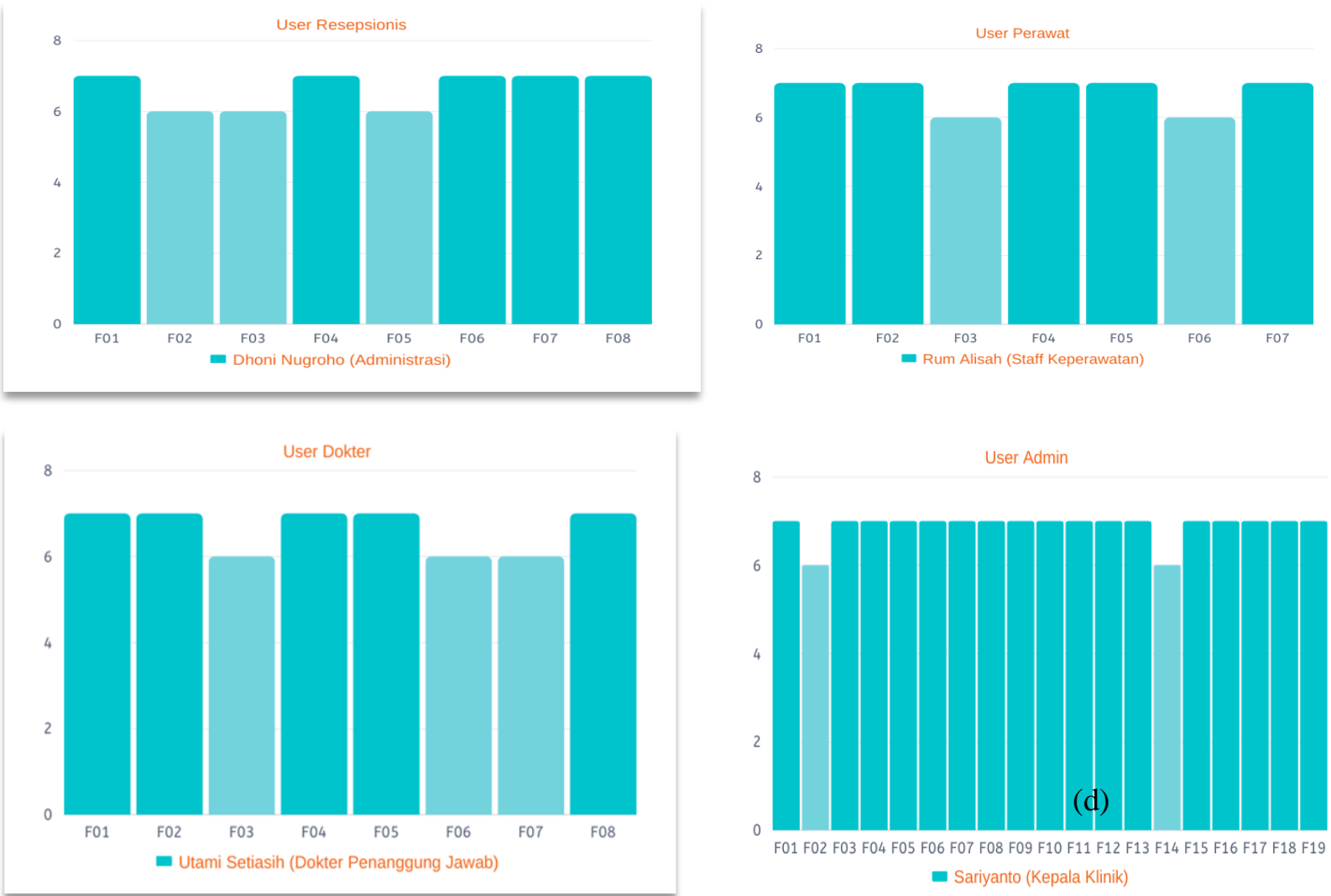

(c)

Gambar 7. Grafik Hasil Pengujian SEQ untuk setiap pengguna. (a) Resepsionis, (b) Staf Keperawatan, (c) Dokter dan (d) Admin

Hasil pengujian dengan metode SEQ adalah semua pengguna berhasil menyelesaikan semua skenario fungsi yang ada dengan rata-rata skala likert yang diberikan untuk setiap skenario fungsi adalah 6 dan 7 (lihat Gambar 7). Maknanya, Sistem Informasi Rekam Medis Klinik PKU Muhammadiyyah Gandrumangu dapat beroperasi dengan baik dan mudah digunakan oleh pengguna. Dengan demikian sistem yang dibuat ini telah menjawab permasalahan dan memenuhi tujuan dari penelitian.

\section{Pengujian dengan metode SUS}

Pada metode SUS ini kuesioner dibagikan kepada empat orang perwakilan yang telah menyelesaikan pengujian SEQ. Tujuan pengujian dengan metode SUS ini yaitu untuk mengetahui apakah sistem dapat mengefisienkan pengelolaan rekam medis di klinik berdasarkan persepsi pengguna setelah menggunakan sistem. Terdapat 10 pertanyaan (lihat Tabel 3) yang setiap pertanyaan diberi skala likert 1-5 level dari sangat tidak setuju sampai dengan sangat setuju. Pertanyaan bernomor ganjil $(1,3,5,7,9)$ merupakan pertanyaan bernada positif. Sedangkan pertanyaan bernomor genap $(2,4,6$, $8,10)$ merupakan pertanyaan bernada negatif. Pembagian kategori kesimpulan metode SUS yaitu Not Acceptable dengan skor direntang 0-50,9; Marginal 51-70,9 ; dan Acceptable 71- 100 (Ardiansyah dan Ghazali, 2016).

Tabel 3. Skenario Pengujian SUS

No Pertanyaan

$1 \quad$ Apakah aplikasi ini mampu membantu dan mempercepat dalam mengelola data rekam medis?

2 Apakah anda perlu menunggu lama untuk mendapatkan hasil yang anda inginkan?

3 Apakah menu pada sistem mudah diingat?

4 Apakah anda merasa sistem ini menghambat kinerja anda?

5 Apakah fitur-fitur pada sistem sudah memenuhi kebutuhan?

6 Apakah sistem ini memberikan hasil yang tidak akurat dan tidak sesuai dengan yang diharapkan?

7 Apakah anda merasa bahwa kebanyakan penguna akan cepat mahir dalam menggunakan sistem ini?

8 Apakah sistem ini kurang membantu dalam mengurangi kesalahan dalam pencatatan rekam medis?

9 Apakah anda yakin dapat menggunakan sistem ini lebih mudah dan lebih cepat saat kedua kalinya? 
$10 \quad$ Apakah anda perlu belajar banyak hal agar bisa mahir dalam menggunakan sistem ini?

Hasil pengujian SUS menunjukkan bahwa rata-rata setiap pertanyaan bernada positif mendapatkan tanggapan positif dengan nilai 4 dan 5 yang artinya pengguna setuju atas pertanyaan yang diajukan. Sedangkan pertanyaan bernada negatif mendapatkan tanggapan yang negatif dengan nilai 1 dan 2 yang artinya pengguna tidak setuju atas pertanyaan yang diajukan.

Tanggapan responden atas pertanyaan-pertanyaan mengindikasikan bahwa : (a) sistem dapat membantu pelaksanaan tugas-tugas responden dalam pengelolaan rekam medik lebih cepat dibandingkan pencatatan konvensional; (b) responden merasa menu dan fitur yang disediakan sistem tidak rumit dan mudah mengingat tata letak dari menu-menu yang ada bahkan dengan keadaan belum lama mengenal atau menggunakan sistem ini. Oleh karena itu sistem ini mudah dipelajari dan yakin bahwa pengguna lain akan cepat mahir dalam menggunakan sistem ini; (c) fitur pada sistem sudah memenuhi kebutuhan untuk melakukan pencatatan dan pengelolaan rekam medis dan sangat membantu responden dalam mengurangi kesalahan dalam pencatatan rekam medis; (d) responden merasa dengan menggunakan sistem ini kinerja mereka akan lebih baik atau meningkat.

Berdasarkan hasil akhir dari perhitungan diperoleh nilai 90,6, dengan nilai tersebut Sistem Informasi Rekam Medis Klinik PKU Muhammadiyyah Gandrumangu masuk dalam kategori acceptable maknanya adalah sistem telah memiliki usability yang excellent menurut para responden.

\section{KESIMPULAN}

Pelayanan kesehatan di Klinik PKU Muhammadiyyah Gandrumang belum didukung oleh teknologi informasi, misalnya proses pendaftaran pasien, dokumentasi rekam medis pasien hingga pembuatan laporan masih menggunakan sistem pencatatan manual. Kondisi ini menimbulkan beragam kendala, jika tidak segera diberikan solusi maka akan menurunkan kualitas pelayanan kesehatan kepada pasien. Oleh karena itu Sistem Informasi Rekam Medis dikembangkan untuk menyelesaikan permasalahan tersebut, menggunakan metode prototyping dengan dua kali iterasi. Pengujian fungsionalitas menggunakan metode SEQ menunjukkan hasil rata-rata skala likert yang diberikan untuk setiap skenario fungsi adalah 6 dan 7. Dengan hasil pengujian yang didapat tersebut dapat disimpulkan bahwa sistem yang dibuat ini dapat beroperasi dengan baik dan mudah digunakan oleh pengguna. Pengujian usabilitas dengan metode SUS memberikan skor 90,6 dengan nilai tersebut menurut para responden sistem memiliki usabilitas yang excellent.

Dengan demikian sistem yang dibuat ini telah menjawab permasalahan dan memenuhi tujuan dari penelitian ini yaitu berhasil membangun sistem informasi rekam medis yang efisien yaitu mudah dalam mengoperasikannya, cepat dan mudah dipelajari, serta cepat dalam menghasilkan data yang akurat dan sesuai dengan yang diharapkan pengguna. Peluang penelitian lanjutan dapat berupa penambahan modul Sistem Pendukung Klinis untuk mendukung diagnosis dokter.

\section{UCAPAN TERIMA KASIH}

Terima kasih penulis sampaikan kepada Program Studi Informatika Universitas Islam Indonesia yang telah memberikan dukungan dana penelitian, dan semua instansi maupun perseorangan yang telah memberikan dukungan moril dan materil selama pelaksanaan penelitian.

\section{DAFTAR PUSTAKA}

Amin, M., Setyonugroho, W., Hidayah, N. (2012). Implementasi Rekam Medik Elektronik: Sebuah Studi Kualitatif. Jurnal Teknik Informatika dan Sistem Informasi, 8(1), 430-442.

Andriani, R., Kusnanto, H., Istiono, W. (2017). Analisis Kesuksesan Implementasi Rekam Medis Elektronik di RS Universitas Gadjah Mada. Jurnal Sistem Informasi, 13(2), 90.

Ardiansyah, Ghazali, I.,M. (2016). Pengujian Usability User Interface dan User Experience Aplikasi e-Reader Skripsi Berbasis Hypertext. Jurnal Ilmiah Teknologi Informasi Terapan, 2(13), 213-220.

Brooke, J. (2013). SUS: A Retrospective. Journal of Usability Studies, 8(2), 29-40.

Erawantini, F., \& Wibowo, S.N. (2019). Implementasi Rekam Medis Elektronik dengan Sistem Pendukung Keputusan Klinis. Jurnal Teknologi Informasi dan Terapan, 6(2), 75-78. Diakses dari http://jtit.polije.ac.id/index.php/jtit/article/view/115

Hakim, N. (2019). Rancang Bangun Sistem Informasi Rekam Medis Menggunakan PHP dan MySQL dengan Metode Pengembangan Waterfall di Klinik Utama Rizqina Benda Sirampog. https://doi.org/.1037//0033-2909.I26.1.78

Kurnia, W. (2019). Desain Interaksi Aplikasi Rekam Medis Berbasis UCD (Studi Kasus : RSUD dr. Soehadi Prijonegoro Sragen). Diakses dari https://www.sematicscholar.org/paper/Desain-Interaksi-Aplikasi-RekamMedis-Berbasis-UCD 
Pressman, R. (2012). Rekayasa Perangkat Lunak Pendekatan Praktisi. Edisi 7. Yogyakarta: Andi Offset

Ramdani, H., Syamsuriansyah, S., \& Andriani, H. (2018). Perancangan Sistem Informasi Sensus Harian Rawat Inap Di Rumah Sakit Bhayangkara Mataram. Jurnal Manajemen Informasi Kesehatan Indonesia, 6(2), 157. https://doi.org/10.33560/.v6i2.202

R.I. (2004). UU No. 29 Tahun 2004 Tentang Praktik Kedokteran, 157-180.

Rusli, A., Rasad, A., Enizar, Irdjati, I., Subekti, I., Suprapta, I. P., \& Mohammad, K. (2006). Manual Rekam Medis. Jurnal Rekam Medis, 2(10), 3-6.

Sauro, J., \& Lewis, J.R. (2012). Quantifying The User Experience : Practical Statistics for User Research. (S.Elliot, Ed.).(I).USA: Elsevier

Satria, Y. A. (2019). Perancangan Sistem Informasi Rekam Medis Berbasis Web pada Poskesdes Jerambah Bolong Kota Jambi. 2504, 1-9.

Subhiyakto, R.E., \& Utomo, W. D. (2017). Analisis Dan Perancangan Aplikasi Pemodelan Kebutuhan Perangkat Lunak Menggunakan Metode Prototyping. Prosiding Seminar Nasional Multi Disiplin Ilmu \& Call For Papers UNISBANK ke-3 (SENDI_U 3), 207, 57-62. 